\title{
Mentha longifolia (L.) Hudson subsp. typhoides (Briq.) Harley var. typhoides'in Hidroksil Radikali ve Hipokloröz Asit Süpürme Aktiviteleri
}

\author{
Mahire BAYRAMOĞLU AKKOYUN ${ }^{1 *}$, Ferda CANDAN ${ }^{2}$ \\ ${ }^{1}$ Siirt University, Department of Biochemistry, Faculty of Veterinary, Siirt, Turkey \\ ${ }^{2}$ Sivas Cumhuriyet University Department of Biochemistry, Faculty of Sciences, Sivas, Turkey \\ (ORCID: 0000-0001-5150-5402)
}

\begin{abstract}
Öz
Çalısmada Mentha longifolia (L.) Hudson subsp. typhoides (Briq.) Harley var. typhoides etanol ekstraktının total antioksidan kapasitesi ile hidroksil radikali $(\mathrm{OH})$ ve hipokloröz asit(HOCI) süpürme aktivitesinin değerlendirilmesi amaçlandı. M. longifolia subsp. typhoides var. typhoides total antioksidan kapasitesi $569 \pm 8.57$ mg AAE/gr olarak belirlendi. Mentha longifolia (L.) Hudson subsp. typhoides (Briq.) Harley var. typhoides etanol ekstraktının, hidroksil radikali ve hipokloröz asit süpürücü aktiviteleri incelendiğinde IC50 değerleri ise sırasıyla $75.09 \pm 2.47 \mathrm{ve} 201.43 \pm 17.99 \mu \mathrm{g} / \mathrm{mL}$ olarak tesbit edildi. Sonuç olarak M. longifolia subsp. typhoides var. typhoides etanol ekstraktının total antioksidan kapasitesi ve radikal süpürme aktivitesi değerlendirildiğinde bitkinin potensiyel bir doğal antioksidan kaynağı olabileceği söylenebilir. Ayrıca, oksidatif strese bağlı olarak ortaya çıkabilecek birçok hastalığın önlenmesi veya tedavisinde terapötik ajanlar olarak yüksek etkiye sahip olabileceği düşünülmektedir.
\end{abstract}

Anahtar kelimeler: Hidroksil radikal, Hipokloröz asit, oksidatif stres

\section{Hydroxyl Radical and Hypochlorous Acid Scavenging Activity of Mentha longifolia (L.) Hudson subsp. typhoides (Briq.) Harley var. typhoides}

\begin{abstract}
The purpose of this study was to investigate the antioxidant potential with hydroxyl radical $(\mathrm{OH})$ and hypochlorous acid(HOCI) scavenging activity of the ethanol extract of Mentha longifolia (L.) Hudson subsp. typhoides (Briq.) Harley var. typhoides. The total antioxidant activity was found to be $569 \pm 8.57 \mathrm{mg}$ AAE/gr of extract. Mentha longifolia (L.) Hudson subsp. typhoides (Briq.) Harley. IC50 values of typhoides ethanol extract, hydroxyl radical and hypochlorous acid were determined as $75.09 \pm 2.47$ and $201.43 \pm 17.99 \mu \mathrm{g} / \mathrm{mL}$ respectively. As a result, the total antioxidant capacity and radical scavenging activity of the plant ethanol extract can be considered as a potential natural antioxidant source of the plant. It is also thought that it may have high effect as therapeutic agents in the protection or treatment of many diseases due to oxidative stres.
\end{abstract}

Keywords: Hydroxyl radical, Hypochlorous acid, oxidative stres

\section{Giriş}

Günümüzde yoğun olarak çalışılan konular arasında olan serbest radikaller ve onların zararlı etkilerini önlemede kullanılan eşsiz bileşikler olan antioksidanlar gün geçtikçe daha fazla önem kazanmaktadır. Reaktif oksijen türleri (ROS) ve azot türleri (RNS), süperoksit başta olmak üzere hidroksil, nitrik oksit radikallerinin yanı sıra hidrojen peroksit ve nitröz asit gibi çeşitli aktifleşmiş oksijen ve azot formlarıdır [1]. Düşük derişimlerde fizyolojik hücre süreçlerinde çalışırlar ancak yüksek derişimlerde lipidler proteinler ve DNA gibi bileşenleri olumsuz yönde etkilerler [2].

*Sorumlu yazar: mahireakkoyun@ siirt.edu.tr

Geliş Tarihi: 23.10.2018, Kabul Tarihi: 12.03.2019 
Reaktif oksijen türleri, özellikle DNA ve proteinler üzerine yıkıcı etkiler gösterirler.[3] Reaktif oksijen türlerinin zararlı etkilerini önlemek için hücreler, reaktif türleri temizleyen antioksidan sistemlere sahiptirler [4]. Biyolojik sistemlerin sağlıklı yürütülebilmesi antioksidanlar ve oksidanlar arasındaki denge ile yakından ilgilidir. Bu dengenin bozulması oksidatif strese yol açarak ateroskleroz, inme, diyabet, Alzehimer, kanser gibi çeşitli hastalıklara yol açar [5]. Serbest radikallerin olumsuz etkilerini ortadan kaldırmada askorbik asit, glutatyon gibi enzimatik olmayan antioksidanlar ve süperoksit dismutaz, katalaz, glutatyon peroksidaz gibi antioksidan enzimler oldukça önemli role sahiptirler [6].

Tıbbi ve aromatik bitkilerin önemli bir bölümünü oluşturan Lamiaceae familyası dünya çapında 6000 den fazla türle temsil edilen önemli bir ailedir. Bu familya Türkiye'de 45 cins ve 574 tür ile bilinir [7]. Akdeniz bölgelerinde, Avrupa, Avustralya ve Kuzey Afrika'da yaygın olarak yetişen Lamiaceae familyasına ait Mentha longifolia popüler bir halk ilacıdır. Bu bitkinin bazı kısımlarının İran başta olmak üzere diğer bazı ülkelerin geleneksel tıbbında kullanıldığı rapor edilmiştir. Aynı zamanda gıda ilaç kozmetik ve hijyen endüstrisinde antiseptik, antikanserojen, balgam söktürücü, sakinleştirici, diüretik, mide bulantısı gibi etkilere karşı kullanıldığı bilinmektedir. Yine yapılan birçok araştırmada bitkinin çeşitli farmakolojik terapatik etkileri ortaya konmuştur [8-9]. Bu sebeple çalışmamızda; M. longifolia subsp. typhoides var. typhoides'in etanol ekstraktının toplam antioksidan kapasitesi ile hidroksil radikal ve hipokloröz asiti süpürme aktivitelerinin değerlendirilmesi amaçlandı.

\section{Materyal ve Metot}

\subsection{Bitkisel Materyal}

M. longifolia subsp. typhoides var. typhoides bitki örnekleri Sivas ili, Gürün ilçesi Gökpınar Gölü çevresinden, Temmuz ayında toplanmıştır. Bitki Sivas Cumhuriyet Üniversitesi, Fen Fakültesi Dr. Öğretim Üyesi Erol Dönmez tarafından tanımlandı ve ED 6112 herbaryum numarası ile Cumhuriyet Üniversitesi, Fen Fakültesi herbaryumunda (CUFH) saklanmaktadır.

\subsection{M. longifolia subsp. typhoides var. typhoides Ekstraktının Hazırlanması}

Çalışmada kullanılan M. longifolia subsp. typhoides var. typhoides'in yer üstü kısımları (yapraklar, saplar ve çiçekler) 1 hafta oda sıcaklığında ve gölgede kurutularak toz haline getirildi. Kurutulan bitki, etanol ile maserasyon tekniğine göre ekstre edildi [10].100 gr bitki örneği termal bozunmayı önlemek için $25^{\circ} \mathrm{C}^{\prime}$ de 24 saat boyunca çalkalamalı inkübatörde $1000 \mathrm{~mL}$ saf etanol (saflık \% 94.0) ile üç kez ekstre edildi. Karışım vakum-filtrasyonu ile ayrıldı. Etanol $45^{\circ} \mathrm{C}^{\prime}$ de rotary evaporator kullanılarak uzaklaştırıldı. Kalan nemin uzaklaştırılması için ekstrakt $45^{\circ} \mathrm{C}$ inkübatörde bekletildi. Ardından kurutulmuş ekstrakt analiz süresine kadar $-18^{\circ} \mathrm{C}$ 'de saklandı.

\subsection{Total Antioksidan Kapasitenin Belirlenmesi}

M. longifolia subsp. typhoides var. typhoides' in etanol ekstresinin total antioksidan aktivitesi (TAC) Prieto ve ark.'nın tanımladığı fosfomolibden yöntemiyle değerlendirildi [11]. $0.3 \mathrm{~mL}$ Mentha longifolia etanol ekstresi $(0.25-1 \mathrm{mg} / \mathrm{mL})$ alınarak, $3 \mathrm{~mL}$ reaktif çözeltisi $(0.6 \mathrm{M}$ sülfürik asit, $28 \mathrm{mM}$ sodyum fosfat ve $4 \mathrm{mM}$ amonyum molibdat) eklendi. Tüpler kapatıldı ve 90 dakika boyunca $95^{\circ} \mathrm{C}$ 'de bekletildi. Ardından numuneler buz banyosunda oda sicaklığına kadar soğutuldu ve $695 \mathrm{~nm}$ dalga boyunda kontrole karşı değerlendirildi. Aynı deneme şartlarında farklı derişimlerde askorbik asit çözeltisi kullanılarak hazırlanan standart çalışma grafiğinden yararlanarak, ekstraktın toplam antioksidan aktivitesi, askorbik asit eşdeğeri (mg AAE/gr) şeklinde ifade edildi.

\subsection{Hidroksil Radikali Süpürme Aktivitesi}

Hidroksil radikali süpürme aktivitesi Kunchandy ve Rao yöntemine göre belirlendi [12]. Yöntemin esas1 $\mathrm{Fe} /$ Askorbat/EDTA/ $\mathrm{H}_{2} \mathrm{O}_{2}$ sistemi ile açığa çıkarılan hidroksil radikalinin, deoksribozu bozundurmasıyla açığa çıkan reaktif ürünlerin $532 \mathrm{~nm}$ dalga boyundaki absorbansına dayanır. Farklı derişimlerdeki bitki 


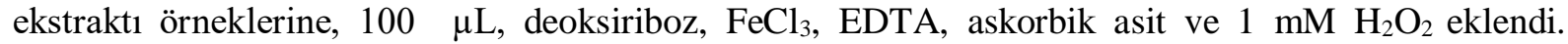
Ardından fosfat tampon ( $\mathrm{pH}$ 7.4) ile hacim 1 mL'ye tamamlandı. Karışım $37^{\circ} \mathrm{C}$ sicaklıkta bir saat bekletildi. Bekletme işleminden sonra tepkime karışımına \% 1'lik tiyobarbitürik asit (TBA) ve \%2.8'lik trikloroasetik asit (TCA) ilave edilerek kaynatıldı. Meydana gelen renkli kompleksin renk şiddeti 532 nm dalga boyunda ölçüldü. Pozitif kontrol olarak, sentetik bir antioksidan ve katkı içeriği olan BHT kullanıld1.

Bitki ekstraktının ve standartın inhibisyon yüzdeleri aşağıdaki eşitlikten hesaplandı;

$$
\% \text { İnhibisyon }=\left[\left(\mathrm{A}_{0}-\mathrm{A}_{1}\right) / \mathrm{A}_{0}\right] * 100
$$

\section{$\mathrm{A}_{0}$, kontrolün absorbans 1}

$\mathrm{A}_{1}$, örnek absorbansı

\subsection{Hipokloroz Asit Süpürme Aktivitesi}

$\mathrm{Bu}$ yöntemin esası katalaz enziminin $\mathrm{HOCl}$ ile $25^{\circ} \mathrm{C}$ 'lik inkübasyonu sonucunda inaktive olmasına dayanmaktadır [13]. Hipokloröz asit (HOCI), deneyden hemen önce, \%10 (v/v) NaOCI çözeltisinin pH'sınin, $0.6 \mathrm{M} \mathrm{H}_{2} \mathrm{SO}_{4}$ ile 6.2'ye ayarlanmasıyla hazırlandı. $235 \mathrm{~nm}$ 'de absorbansı ölçüldü ve molar absorpsiyon katsayısı $100 \mathrm{M}^{-1} \mathrm{~cm}^{-1}$ kullanılarak HOCI derişimi belirlendi. Süpürme aktivitesi, 404 nm'de katalazın absorbansındaki azalmanın belirlenmesiyle değerlendirildi. Tepkime karışımının son hacmi $1 \mathrm{~mL}$ olacak şekilde, $50 \mathrm{mM}$ fosfat tamponu (pH 6.8), katalaz $(7.2 \mu \mathrm{M})$, HOCI $(8.4 \mathrm{mM})$ ve artan derişimlerde $(10-300 \mu \mathrm{g} / \mathrm{mL})$ bitki özütü eklendi. Analiz karışımının $25{ }^{\circ} \mathrm{C}$ 'de 20 dakikalık inkübasyonu sonucunda süpürücü varlığında ve yokluğunda ölçülen absorbans değerleri kullanılarak hipokloroz süpürme aktivitesi belirlendi [14]. Güçlü bir $\mathrm{HOCl}$ süpürücüsü olan askorbik asit standart olarak kullanıldı. Ekstraktın ve standartın inhibisyon yüzdeleri hidroksil radikali süpürme aktivitesindeki eşitlikle hesaplandı.

\section{6. İstatistiksel Analiz}

Tüm deneysel veriler üç tekrarlı olup, sonuçlar standart sapma olarak verilmiştir. Sigma Plot Grafik ve İstatistik Program1 9.0 kullanılarak; çizilen grafiklerden IC50 değerleri belirlenmiştir.

\section{Bulgular ve Tartışma}

M. longifolia subsp. typhoides var. typhoides etanol ekstraktının, total antioksidan kapasitesi spektrofotometrik olarak $695 \mathrm{~nm}$ dalga boyunda belirlendi. Genel olarak yüksek absorbans güçlü antioksidan aktiviteyi tanımlar. Buna bağlı olarak M. longifolia subsp. typhoides var. typhoides etanol ekstraktının toplam antioksidan kapasitesi $569 \pm 8.57 \mathrm{mg}$ AAE/gr olarak belirlendi.

M. longifolia subsp. typhoides var. typhoides ethanol ekstraktının farklı derişimlerde hidroksil radikalini ve hipokloröz asiti inhibe eden değerleri Tablo 1'de verildi. Mentha longifolia (L.) Hudson subsp. typhoides (Briq.) Harley var. typhoides etanol ekstraktının, hidroksil radikali ve hipokloröz asiti süpürücü aktiviteleri ise Tablo 2'de sunuldu. Buna göre bitki etanol ekstraktı ve BHT'nin hidroksil radikalini süpürücü aktiviteleri incelendiğinde; IC50 değerleri sirasıyla $75.09 \pm 2.47 \mu \mathrm{g} / \mathrm{mL}$ ve $49.20 \pm 1.83 \mu \mathrm{g} / \mathrm{mL}$ olarak belirlendi. M. longifolia subsp. typhoides var. typhoides. hipokloröz asit(HOCI) süpürme aktivitesi değerlendirildiğinde ise; en yüksek inhibisyon değerinin $300 \mu \mathrm{g} / \mathrm{mL}$ derişimde $\% 63.59 \pm 3.06$ olduğu, bitki etanol ekstraktı ve pozitif kontrol olarak kullanılan askorbik asitin hipokloröz asit süpürücü aktiviteleri incelendiğinde ise sirasiyla IC50=201.43 $\pm 17.99 \mu \mathrm{g} / \mathrm{mL}$, IC50 $=267.49 \pm 5.16 \mu \mathrm{g} / \mathrm{mL}$ olduğu tesbit edildi. $\mathrm{HOCl}$, antioksidan enzim olan katalazı, heme-prostetik grubun yıkılması yoluyla inaktive etme yeteneğine sahiptir. Ekstrakt varlığında katalazın inaktive olmasının inhibisyonu ise $\mathrm{HOCl}$ süpürücü aktivitesini göstermektedir. Sonuç olarak; M. longifolia subsp. typhoides var. typhoides ekstraktının, hipokloröz asidi, bir antioksidan olan askorbik asitten daha etkin olarak süpürdüğ̈ görüldü. 
Tablo 1. M. longifolia subsp. typhoides var. typhoides etanol ekstraktının Hidroksil Radikali ve Hipokloröz asit \% inhibisyon değerleri

\begin{tabular}{lcc}
\hline Derişim $(\mu \mathrm{g} / \mathrm{mL})$ & $\begin{array}{c}\text { Hidroksil Radikali süpürme } \\
(\% \text { inhibisyon })\end{array}$ & $\begin{array}{c}\text { Hipokloröz asit süpürme } \\
(\% \text { inhibisyon })\end{array}$ \\
\hline 10 & $30.15 \pm 0.91$ & - \\
20 & $34.23 \pm 074$ & - \\
40 & $42.17 \pm 1.14$ & - \\
80 & $51.34 \pm 2.05$ & $10.81 \pm 1.12$ \\
100 & $54.08 \pm 1.79$ & $26.72 \pm 0.97$ \\
120 & $62.70 \pm 2.83$ & $38.11 \pm 3.21$ \\
140 & $66.56 \pm 1.67$ & $43.24 \pm 1.98$ \\
200 & $73.45 \pm 2.14$ & $48.91 \pm 1.21$ \\
240 & - & $54.17 \pm 2.45$ \\
280 & - & $61.07 \pm 2.30$ \\
300 & - & $63.59 \pm 3.06$ \\
\hline
\end{tabular}

Tablo 2. M. longifolia subsp. typhoides var. typhoides ve pozitif kontrollerin, Hidroksil Radikali ve Hipokloröz asit IC50 değerleri

\begin{tabular}{lll}
\hline Aktivite & Ekstrakt/pozitif kontrol & $\begin{array}{l}\text { IC50 } \\
\boldsymbol{\mu g} / \mathbf{m L}\end{array}$ \\
\hline $\begin{array}{l}\text { Hidroksil radikali }(\mathrm{OH} \bullet) \\
\text { süpürme }\end{array}$ & Mentha longifolia & $75.09 \pm 2.47$ \\
& BHT & $49.20 \pm 1.83$ \\
\hline $\begin{array}{l}\text { Hipokloröz asit }(\mathrm{HOCl}) \\
\text { süpürme }\end{array}$ & Mentha longifolia & $201.43 \pm 17.99$ \\
& Askorbik asit & $267.49 \pm 5.16$ \\
\hline
\end{tabular}

Yüksek düzeydeki serbest radikaller veya aktif oksijen türleri çeşitli biyokimyasal ve fizyolojik lezyonlara yol açan ve sıklıkla metabolik bozulma ve hücre ölümü ile sonuçlanan oksidatif stres oluştururlar. Mentha L cinsi Asya, Avrupa ve Güney Afrika'nın 1lıman bölgelerinde nemli ve ıslak yerlerde yetişen yirmibeşten fazla türü içerir. Mentha 'nın yaprak çiçek ve sapları bitkisel çay olarak tüketimlerinin yanı sıra, dünya genelinde uçucu yağ, likör ve şekerleme endüstrisinde lezzetlendirmede, parfüm üretiminde medikal amaçlı olarak kullanılmaktadır [15]. Yine farklı Mentha türlerinin antiinflmatuar, karminatif, antiemetik, antispazmodik etkileri nedeniyle bulant,, bronşit, şişkinlik anoreksiya, ülseratif kolit ve karaciğer şikâyetlerinin tedavisinde önemli olduğu bildirilmiştir [16]. Bu özelliklerden yola çıkılarak çalışmamızda $M$. longifolia subsp. typhoides var. typhoides bitkisinin toplam antioksidan kapasitesini aynı zamanda hidroksil radikali ve hipokloröz asiti süpürerek göstermiș olduğu antioksidan aktivitesinin belirlenerek, bundan sonra yapılacak olan çalışmalara bir referans teşkil etmesi amaçlandi. M. longifolia subsp. typhoides var. typhoides'in toplam antioksidan kapasitesi $569 \pm 8.57 \mathrm{mg}$ AAE /gr olarak belirlendi. Yüksek antioksidan kapasite yüksek fenol ve flavanoid içeriği ile açıklanabilir. Aynı zamanda bitkilerin fenol içeriklerinin antioksidan özelliklerine doğrudan katkı sağladığı bilinmektedir [17]. Daha önce yapılan çalışmalarda Mentha türlerinin antioksidan aktivite ve fenolik içerikleri arasında güçlü bir bağlantının olduğu belirtilmiştir [18]. Stanisavljevic ve arkadaşları farklı kurutma tekniklerinin Mentha longifolia (L) Hudson etanol ekstraktında fenol, flavanoid ve total antioksidan kapasite üzerine etkilerini değerlendirmişler, doğal olarak kurutulan örneklerde fenol, flavanoid içeriğinin ve buna bağlı olarak antioksidan kapasiteninde diğer farklı kurutma yöntemlerine oranla oldukça iyi olduğunu belirtmişlerdir [19]. Mentha longifolia ve Mentha pulegium gibi iki farkl1 Mentha türünde fenol ve flavanoid içeriği değerlendirmiş ve Mentha longifolia metanol ekstraktının, aktif bileşenler yönünden oldukça zengin olduğu tesbit edilmişdir [20]. Diğer bir çalışmada ise Mentha türlerinin kimyasal bileşimi ve biyolojik aktivite yönünden oldukça aktif oldukları, Mentha longifolia'nın yaprak çiçek tohum gibi farklı kısımlarının antimikrobiyal, karminatif, stimulant, antispazmodik sedatif ve diüretik etkiler gösterdiği belirtilmiştir [8]. Üç farklı Mentha türünün total fenol ve flavanoid içeriği belirlenmiş, buna bağl1 olarak antioksidan kapasiteleri değerlendirilmiştir [21]. Yapılan farklı bir çalışmada Mentha longifolia'nın fenol ve flavanoid yönünden oldukça zengin olduğu ve bitkiden izole edilen bir flavanoid türünün antimutajenik etkiye sahip olduğunu belirtmişlerdir [22]. 
Bahadori ve arkadaşları tarafindan yapılan bir çalışma ise; Mentha longifolia var. colliantha etanol ekstraktının fenolik profili değerlendirilmiş ve güçlü antioksidan etkiye sahip olduğu belirtilmiştir [23]. Akşit ve arkadaşları tarafindan yapılan bir başka çalışmada; Mentha longifolia (L.) Hudson subsp. typhoides (Briq.) Harley var. typhoides uçucu yağının kimyasal bileşimi GC-MS analizi yapılarak değerlendirilmiştir [24]. Benzer şekilde Tokat ve ilçelerinde yetişen Mentha longifolia (L.) Hudson subsp. typhoides (Briq.) Harley var. typhoides türünde yer aldığ 1 dört yabani Mentha türünün uçucu yağlarının kimyasal analizleri ve antioksidan kapasiteleri değerlendirilmiştir. En önemli bileşenlerin linalool, menthone, pulegon, izomenton ve piperitonoksit olduğu tesbit edilmiştir. Türlerin uçucu yağlarının lipid peroksidasyonu, süperoksit radikali, hidrojen peroksit süpürücü aktivitelerinin etkili olduğu rapor edilmiştir [25].

Biyolojik sistemlerde en önemli serbest radikaller, radikal oksijen türevleridir. Reaktif oksijen türleri sadece oksijen değil aynı zamanda hipokloröz asit (HOCI) gibi, oksijen radikali üretiminde yer alan radikal olmayan oksijen türlerini de içerirler [26]. Yüksek miktarlarda serbest radikaller hücrenin özellikle lipid, protein, nükleik asit gibi önemli yapılarına ciddi düzeyde hasara neden olurlar [27]. Biyolojik sistemlerde $\mathrm{HOCI}$, fagositik hücrelerde miyeloperoksidaz- $\mathrm{H}_{2} \mathrm{O}_{2}-\mathrm{klorür}$ enzim sistemi tarafindan üretilen oksitleyici ve klorlayıcı bir maddedir.[28] Hipokloröz asidin DNA, protein ve kolesterol, plasmalojenler ve doymamış yağ asil zincirleri gibi lipitleri içeren birtakım biyolojik hedeflerle tepkimeye girdiği ve diğer zararlı ROS'ların üretimine katkı sağladığı bilinmektedir [29-30]. Çalışmada M. longifolia subsp. typhoides var. typhoides'in etanol ekstraktının, biyolojik sistemlerdeki en reaktif ve hasar verici radikal türü olan hidroksil radikalini $200 \mu \mathrm{g} / \mathrm{mL}$ derişimde $\% 73.45 \pm 2.14$ oranında inhibe ettiği belirlendi. Bitki ekstraktının Hipokloröz asidi ise $300 \mu \mathrm{g} / \mathrm{mL}$ derişimde $\% 63.59 \pm 3.06$ inibisyona uğrattığı belirlendi. Bu değerlerden $M$. longifolia subsp. typhoides var. typhoides'in hidroksil radikali ve hipokloröz asidin inhibisyonunda etkin olduğu görüldü. Elde edilen bulgulardan yararlanarak, bitki etanol ekstraktın hidroksil radikali ve hipokloröz asit IC50 değerleri, BHT, askorbik asit gibi antioksidan özellikleri bilinen kontroller ile karşılaştırıldı. M. longifolia subsp. typhoides var. typhoides'in hidroksil radikalini süpürücü aktivitesi değerlendirildiğinde IC50 $75.09 \pm 2.47 \mu \mathrm{g} / \mathrm{mL}$ olarak hesaplanırken, sentetik antioksidan olan BHT'nin ise IC50 değeri $49.20 \pm 1.83 \mu \mathrm{g} / \mathrm{mL}$, olarak belirlendi. M. longifolia subsp. typhoides var. typhoides' in hipokloröz asit süpürücü etkisi ise güçlü bir doğal antioksidan bileşiklerden olan askorbik asit ile karşılaştırıldı. Sonuçlar M. longifolia subsp. typhoides var. typhoides'in hipokloröz asiti $(\mathrm{IC} 50=201.43 \pm 17.99 \mu \mathrm{g} / \mathrm{mL})$, güçlü doğal antioksidan bileşiklerden olan askorbik asitten $(\mathrm{IC} 50=267.49 \pm 5.16 \mu \mathrm{g} / \mathrm{mL})$ daha etkin bir şekilde süpürdüğünü gösterdi. Belirlenen bu IC50 değeri, Türk halk hekimliğinde mide ülserleri ve mide hastalıklarına karşı kullanılan Mentha türlerinin bu özelliğini desteklemek açısından oldukça önem arz etmektedir [31-32]. Çünkü oksidan bir madde olan hipokloröz asit, mide ülserlerinde görülen mide hasarına bağlı olan mikrobisid monokloramini üretmek için insan midesinde Helicobacter pylori tarafindan üretilen amonyakla tepkimeye girer [33-34]. Bu nedenle, $\mathrm{HOCl}$ ile savaşabilen ilaç ve bitki ekstrelerinin değerlendirilmesi oldukça önemlidir. Yapılan literatür taramalarında, farklı lokasyonlardan toplanan Mentha longifolia L. Hudsons subsp. bitki örneklerinden hazırlanan etanol ekstraktının antioksidan ve antimikrobiyal potansiyele sahip olduğu gözlenmiştir [7]. Mentha longifolia L ve Mentha pulegium uçucu bileşenleri değerlendirilmiş fenol ve flavanoid yönünden iyi kapasiteye sahip olduğu belirlenmiştir. Yine methanol ekstraktlarının, DPPH radikalini ve önemli bir serbest radikal olan süperoksit radikalini süpürmede etkin olduğu tesbit edilmiştir [20]. Yine farklı bir çalışmada M. spicata (L.), M. pulegium (L.) ve M. rotundifolia (L.) Huds gibi mentha türlerinin DPPH radikalini süpürmede etkin oldukları belirtilmiştir [21]. Bu çalışmalara ilave olarak, yapılan bu çalışma ile M. longifolia subsp. typhoides var. typhoides'in hidroksil radikali ve hipokloröz asiti süpürücü özelliği ortaya konulmuştur.

\section{Sonuç ve Öneriler}

Sonuç olarak; Çalışmamızda M. longifolia subsp. typhoides var. typhoides'in yüksek antioksidan kapasitesiye sahip olduğu belirlenmiştir. Ayrıca bitkinin etanol ekstraktının, önemli bir reaktif oksijen türü olan hidroksil radikalini süpürmede etkin olduğu tesbit edilmiştir. Ekstraktın, hipokloröz asiti süpürmede, doğal antioksidan molekül olan askorbik asit ile kıyaslandığında daha etkin olduğu görülmüştür. Tüm bu sonuçlardan M. longifolia subsp. typhoides var. typhoides' in potensiyel bir doğal 
antioksidan kaynağı olabileceği ve oksidatif strese bağlı olarak ortaya çıkacak dejeneratif hastalıkların önlenmesinde veya yavaşlatılmasında katkısı olabileceği düşünülmektedir.

\section{Teşekkür}

Mentha longifolia (L.) Hudson subsp. typhoides (Briq.) Harley var. typhoides tanımlanmasında Sivas Cumhuriyet Üniversitesi, Fen Fakültesi Dr. Öğretim Üyesi Erol Dönmez teşekkür ederiz.

\section{Kaynaklar}

[1] Özgen U., Mavi A., Terzi Z., Yıldırım A., Coşkun M., Houghton P.J. 2006. Antioxidant properties of some medicinal Lamiaceae (Labiatae) species. Pharmaceutical biology, 44 (2): 107112.

[2] Birben E., Sahiner U.M., Sackesen C., Erzurum S., Kalayci O. 2012. Oxidative stress and antioxidant defense. World Allergy Organization Journal, 5 (1): 9.

[3] Kasprzak K.S. 2002. Oxidative DNA and protein damage in metal-induced toxicity and carcinogenesis1, 3. Free Radical Biology and Medicine, 32 (10): 958-967.

[4] Iwasaki A., Gagnon C. 1992. Formation of reactive oxygen species in spermatozoa of infertile patients. Fertility and sterility, 57 (2): 409-416.

[5] Letelier M.E., Molina-Berríos A., Cortés-Troncoso J., Jara-Sandoval J., Holst M., Palma K., González-Lira V. 2008. DPPH and oxygen free radicals as pro-oxidant of biomolecules. Toxicology in vitro, 22 (2): 279-286.

[6] Alscher R.G., Donahue J.L., Cramer C.L. 1997. Reactive oxygen species and antioxidants: relationships in green cells. Physiologia Plantarum, 100 (2): 224-233.

[7] Sevindik M., Akgul H., Pehlivan M., Selamoglu Z. 2017. Determination of therapeutic potential of Mentha longifolia ssp. longifolia. Fresen Environ Bull, 26, 4757-4763.

[8] Mikaili P., Mojaverrostami S., Moloudizargari M., Aghajanshakeri S. 2013. Pharmacological and therapeutic effects of Mentha longifolia L. and its main constituent, menthol. Ancient science of life, 33 (2): 131.

[9] Mimica-Dukic N., Popovic M., Jakovljevic V., Szabo A., Gašic O. 1999. Pharmacological studies of Mentha longifolia phenolic extracts. II. Hepatoprotective activity. Pharmaceutical biology, 37 (3): 221-224.

[10] Bandar H., Hijazi A., Rammal H., Hachem A., Saad Z., Badran B. 2013. Techniques for the extraction of bioactive compounds from Lebanese Urtica Dioica. American Journal of Phytomedicine and Clinical Therapeutics, 1 (6): 507-513.

[11] Prieto P, Pineda M, Aguilar M. 1999. Spectrophotometric quantitation of antioxidant capacity through the formation of a phosphomolybdenum complex: specific application to the determination of vitamin E. Anal Biochem, 269: 337-341.

[12] Kunchandy E., Rao M.N.A. 1990. Oxygen radical scavenging activity of curcumin. Int. J. Pharmacog, 58: 237-240.

[13] Aruoma OI, Halliwell B. 1987. Action of hypochlorous acid on the antioxidant protective enzymes superoxide dismutase, catalase and glutathione peroxidase. Biochem J 248: 973- 97.

[14] Pedraza-Chaverrí J., Arriaga-Noblecía G., Medina-Campos O.N. 2007. Hypochlorous acid scavenging capacity of garlic. Phytotherapy Research: An International Journal Devoted to Pharmacological and Toxicological Evaluation of Natural Product Derivatives, 21 (9); 884-888.

[15] Gulluce M., Sahin F., Sokmen M., Ozer H., Daferera D., Sokmen A., Ozkan H. 2007. Antimicrobial and antioxidant properties of the essential oils and methanol extract from Mentha longifolia L. ssp. longifolia. Food chemistry, 103 (4): 1449-1456.

[16] Singh S., Das S.S., Singh G., Perotti M., Schuff C., Catalán C.A. 2015. In vitro antioxidant potentials and chemistry of essential oils and oleoresins from fresh and sun-dried Mentha longifolia L. Journal of Essential Oil Research, 27 (1): 61-69.

[17] Djeridane A., Yousfi M., Nadjemi B., Boutassouna D., Stocker P., Vidal N. 2006. Antioxidant activity of some Algerian medicinal plants extracts containing phenolic compounds. Food chemistry, 97 (4): 654-660. 
[18] Abootalebian M., Keramat J., Kadivar M., Ahmadi F., Abdinian M. 2016. Comparison of total phenolic and antioxidant activity of different Mentha spicata and M. longifolia accessions. Annals of Agricultural Sciences, 61 (2): 175-179.

[19] Stanisavljevic D.M., Stojicevic S.S., Dordevic S.M., Zlatkovic B.P., Velickovic D.T., Karabegovic I.T., Lazic M.L. 2012. Antioxidant activity, the content of total phenols and flavonoids in the ethanol extracts of Mentha longifolia (L.) Hudson dried by the use of different techniques. Chemical Industry and Chemical Engineering Quarterly, 18 (3): 411-420.

[20] Hajlaoui H., Trabelsi N., Noumi E., Snoussi M., Fallah H., Ksouri R., Bakhrouf A. 2009. Biological activities of the essential oils and methanol extract of tow cultivated mint species (Mentha longifolia and Mentha pulegium) used in the Tunisian folkloric medicine. World Journal of Microbiology and Biotechnology, 25 (12): 2227-2238.

[21] Fatiha B., Didier H., Naima G., Khodir M., Martin K., Léocadie K., Pierre D. 2015. Phenolic composition, in vitro antioxidant effects and tyrosinase inhibitory activity of three Algerian Mentha species: M. spicata (L.), M. pulegium (L.) and M. rotundifolia (L.) Huds (Lamiaceae). Industrial crops and products, 74: 722-730.

[22] Orhan F., Barış Ö., Yanmış D., Bal T., Güvenalp Z., Güllüce M. 2012. Isolation of some luteolin derivatives from Mentha longifolia (L.) Hudson subsp. longifolia and determination of their genotoxic potencies. Food chemistry, 135 (2): 764-769.

[23] Bahadori M.B., Zengin G., Bahadori S., Dinparast L., Movahhedin N. 2018. Phenolic composition and functional properties of wild mint (Mentha longifolia var. calliantha (Stapf) Briq.). International Journal of Food Properties, 21 (1): 183-193

[24] Aksit H., Demirtas I., Telci I., Tarimcilar G. 2013. Chemical diversity in essential oil composition of Mentha longifolia (L.) Hudson subsp. typhoides (Briq.) Harley var. typhoides from Turkey. Journal of essential oil research, 25 (5): 430-437.

[25] Ozen T., Telci I., Gul F., Demirtas I. 2017. Chemical Analyzes and Antioxidant Activities of Essential Oils of Four Wild Mentha Species Growing in the Tokat and Its Districts. International Journal of Chemistry and Technology, 1 (1): 46-57.

[26] Battino M., Bullon P., Wilson M., Newman H. 1999. Oxidative injury and inflammatory periodontal diseases: the challenge of anti-oxidants to free radicals and reactive oxygen species. Critical Reviews in Oral Biology \& Medicine, 10 (4): 458-476.

[27] Valko M., Rhodes C., Moncol J., Izakovic M.M., Mazur M. 2006. Free radicals, metals and antioxidants in oxidative stress-induced cancer. Chemico-biological interactions, 160 (1): 1-40.

[28] Pullar J.M., Vissers M.C., Winterbourn C.C. 2000. Living with a killer: the effects of hypochlorous acid on mammalian cells. IUBMB life, 50 (4-5): 259-266.

[29] Mika D., Guruvayoorappan C. 2011. Myeloperoxidase: the yin and yang in tumour progression. Journal of experimental therapeutics \& oncology, 9 (2): 93-100.

[30] Panasenko O.M., Gorudko I.V., Sokolov A.V. 2013. Hypochlorous acid as a precursor of free radicals in living systems. Biochemistry (Moscow), 78 (13): 1466-1489

[31] Senkardes I., Tuzlaci E. 2014. Some Ethnobotanical Notes from Gundogmus District (Antalya/Turkey). Clinical and Experimental Health Sciences, 4 (2): 63.

[32] Arasan S., Kaya I. 2015. Some important plants belonging to asteraceae family used in folkloric medicine in Savur (Mardin/Turkey) area and their application areas. J Food Nutr Res., 3: 337340.

[33] Dekigai H., Murakami M., Kita T. 1995. Mechanism ofhelicobacter pylori-associated gastric mucosal injury. Digestive diseases and sciences, 40 (6): 1332-1339.

[34] Lapenna D., Cuccurullo F. 1996. Hypochlorous acid and its pharmacological antagonism: an update Picture. General pharmacology, 27 (7): 1145-1147. 